\title{
Penerapan Algoritma Support Vector Machine Dalam Sentimen Analisis Terkait Kenaikan Tarif BPJS Kesehatan
}

\author{
Putu Mega Nirmala Dharmapatni ${ }^{1}$, Ni Luh Putu Merawati*2 \\ 1,2 Jurusan Teknologi Informasi, Universitas Bumigora \\ meganirmala14@gmail.com¹‥putu.mera@universitasbumigora.ac.id²
}

\begin{abstract}
Abstrak
Jejaring sosial adalah alat komunikasi yang sangat populer di kalangan masyarakat salah satunya adalah jejaring sosial twitter. Jumlah tweets berkembang pesat karena kesederhanaan dan kemudahan penggunaannya menjadi alasan twitter lebih populer di kalangan masyarakat Indonesia dalam berkomunikasi. Twitter banyak digunakan sebagai media promosi produk, iklan, kampanye politik maupun sebagai sarana dalam menyampaikan pendapat terkait kritik, saran, isu-isu serta opini-opini yang sifatnya publik seperti pandangan netizen terhadap kebijakan baru pemerintah dan lain sebagainya. Salah satu kebijakan pemerintah yang sedang ramai diperbincangan oleh netizen di jejaring sosial twitter adalah kenaikan tarif BPJS kesehatan. BPJS Kesehatan (Badan Jaminan Kesehatan dan Sosial) adalah Badan Usaha Milik Negara, besarnya jumlah pengguna BPJS menyebabkan BPJS harus menyediakan layanan umpan balik kepada pengguna untuk mengetahui respon pengguna terhadap layanan BPJS. Analisis sentimen atau disebut juga dengan penambangan pendapat adalah suatu bidang dalam menganalisis pendapat seseorang ataupun sekelompok orang mengenai suatu permasalahan yang tersedia untuk melihat respon masyarakat terhadap permasalahan tersebut. Metode SVM merupakan salah satu metode yang baik untuk digunakan dalam pengkalsifikasian data yang berjumlah banyak, terutama terkait dengan sentimen analisis. Pada penelitian ini akan dilakukan analisis sentimen masyarakat melalui media twitter terhadap kenaikan tarif BPJS Kesehatan menggunakan metode SVM untuk melihat respon masyarakat terhadap kebijakan tersebut. Berdasarkan hasil klasifikasi menggunakan algoritma SVM pada 671 sample data tedapat 271 data yang setuju dengan kebijakan yang dibuat serta 400 data yang tidak setuju terhadap kebijakan.
\end{abstract}

Kata Kunci : BPJS Kesehatan, Klasifikasi Support Vector Machine, Sentimen Analisis, Twitter

\begin{abstract}
Social networking is a communication tool that is very popular among the public, one of them is twitter. The number of tweets is growing rapidly because its simplicity and ease of use is the reason Twitter is more popular among Indonesians citizen. Twitter is widely used as a promotional medium of products, advertisements, political campaigns and as a means of conveying related criticisms, suggestions, issues and opinions of a public nature such as netizen views on the government's new policies and so on. One of the government's policies that is being discussed by netizens on social network twitter is the tariff on bpjs health. BPJS Kesehatan (Health and Social Security Agency) is a state-owned enterprise, the large number of BPJS users causes BPJS to provide feedback services to users to know the user's response to BPJS services. Sentiment analysis or so-called mining if there is anything in the analysis of Asia or sekeke people about a problem that is available to see the community's response to the problem. The SVM method is one of the good methods for use in a lot of calcification data, especially when it comes to analytical sentiment. In this study will be conducted public analysis through twitter media against BPJS health tariff using SVM method to see the public against the same policy. Based on the classification results using the SVM algorithm on 671 sample data, there are 271 data that agree with the policies made and 400 data that do not agree with the policy.
\end{abstract}

Keywords : BPJS Kesehatan, Classification, Support Vector Machine, Sentiment Analysis, Twitter

\section{PENDAHULUAN}

Perkembangan jejaring sosial sebagai alat komunikasi sangat populer di masyarakat sebagai salah satu media untuk berkomunikasi salah satunya adalah jejaring sosial Twitter. Berdasarkan data yang dirilis oleh Twitter Indonesia pada tahun 2016 menyebutkan bahwa Indonesia merupakan salah satu pengguna aktif yang produktif menulis tweets dengan presentase $77 \%$ pengguna, hal tersebut dapat di tunjukkan dari jumlah tweets yang dihasilkan sepanjang 2016 yang mencapai 4,1 miliar tweets. Jumlah tweets berkembang pesat karena 
kesederhanaan dan kemudahan penggunaannya menjadi alasan Twitter lebih populer di kalangan masyarakat Indonesia dalam berkomunikasi. Twitter banyak digunakan sebagai media promosi produk, iklan, kampanye politik maupun sebagai sarana dalam menyampaikan pendapat terkait kritik, saran, isu-isu serta opini-opini yang sifatnya publik seperti pandangan netizen terhadap kebijakan baru pemerintah dan lain-lain sehingga informasi yang terkandung pada tweets ini sangat berharga sebagai data pendukung dalam pengambilan kebijakan[1][2].

BPJS Kesehatan adalah Badan Usaha Milik Negara yang khusus ditugaskan oleh pemerintah untuk mengelola kesehatan seluruh rakyat Indonesia yang telah terdaftar secara resmi. Besarnya jumlah pengguna BPJS menyebabkan BPJS harus menyediakan layanan umpan balik kepada pengguna untuk mengetahui respon pengguna terhadap layanan BPJS. Salah satu kebijakan pemerintah yang sedang ramai diperbincangan oleh netizen di jejaring sosial twitter adalah kenaikan harga BPJS kesehatan.Analisis sentimen atau disebut juga dengan penambangan pendapat adalah suatu bidang dalam menganalisis pendapat orang, evaluasi, penilaian, sikap dan emosi kepada suatu entitas seperti produk, layanan, organisasi, individu, masalah, acara dan topik. Fokus utama analisis adalah untuk mengekspesikan sentiment yang mencakup opini positif dan opini negatif[3][4].

Metode SVM merupakan salah satu metode yang baik untuk digunakan dalam pengkalsifikasian data yang berjumlah banyak, terutama terkait dengan sentimen analisis[5], namun banyak penelitian yang dikalukan sebelumnya hanya membahas sentimen analisis dalam ruang lingkup yang terbatas dan jarang mengangkat tema menegenai kebijakan badan pemerintahan yang merupakan lembaga negara. Oleh karena itu pada penelitian ini akan dilakukan analisis sentimen masyarakat melalui media sosial twitter terhadap kenaikan tarif BPJS Kesehatan, yang diatur oleh Peraturan Presiden nomor 64 tahun 2020 tentang perubahan kedua atas Peraturan Presiden nomor 82 tahun 2018 menggunakan metode SVM untuk melihat respon masyarakat terhadap kebijakan tersebut, serta melihat tingkat kecocokan metode SVM dalam mengklasifikasikan kalimat ke dalam kelas positif dan negatif.

\section{METODOLOGI}

\subsection{Tahapan Penelitian Secara Umum}

Tahapan pertama dalam penelitian ini adalah melakukan indentifikasi masalah yakni terkait dengan kenaikan tarif BPJS Kesehatan berdasarkan
Peraturan Presiden Nomor 64 Tahun 2020 Tentang Perubahan Kedua Atas Peraturan Presiden Nomor 82 Tahun 2018.

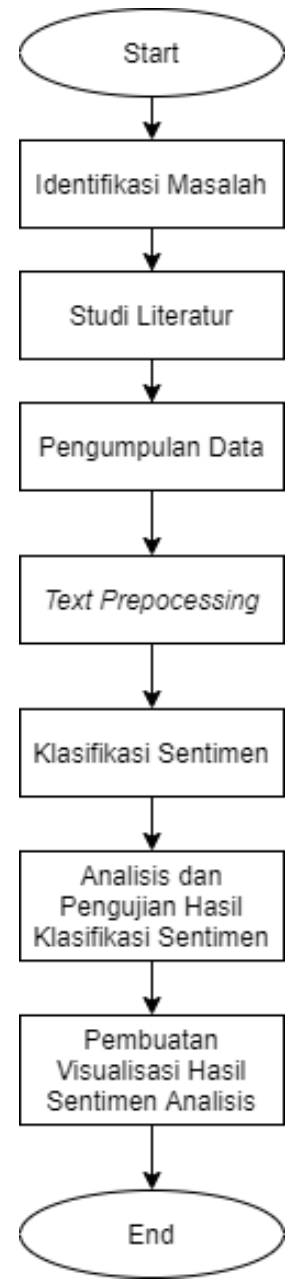

Gambar 1 Tahapan Penelitian Secara Umum

Studi literatur dilakukan untuk memperoleh gambaran, rujukan maupun referensi terkait topik permasalahan yang akan diangkat berdasarkan pada penelitian-penelitian lain yang telah dilakukan sebelumnya. Pengumpulan data atau crawling data merupakan proses penarikan data tweet dari media sosial twitter. Data yang digunakan dalam penelitian ini adalah data primer, yaitu data yang diambil langsung oleh penulis dari media sosial twitter. Data tersebut berupa tweets yang mencantumkan kata BPJS dan kenaikan tarif di dalamnya.

Data yang digunakan dalam penelitian ini berupa data tweets berisi kata sesuai topik yang sudah ditentukan untuk diteliti yaitu kenaikan tarif BPJS. Tweets data yang diambil dari bulan Januari 2020 sampai Juni 2020. Data tweets kemudian akan melalui proses preprocessing yaitu mengolah data mentah menjadi data yang lebih bersih untuk proses kalsifikasi. Sebelum proses klasifikasi dilakukan data hasil preprocessing akan dibagi kedalam data 
training dan data testing. Data training adalah data yang akan digunakan untuk membentuk model pembelajaran dalam menentukan hasil sentimen. Setelah proses klasifikasi sentimen dilakukan selanjutnya adalah mengukur tingkat akurasi metode support vector machine dalam mengkasifikasikan sentimen kemudian hasil akhir dari proses klasifikasi adalah pembuatan visualisasi.

\subsection{Deskripsi Sistem}

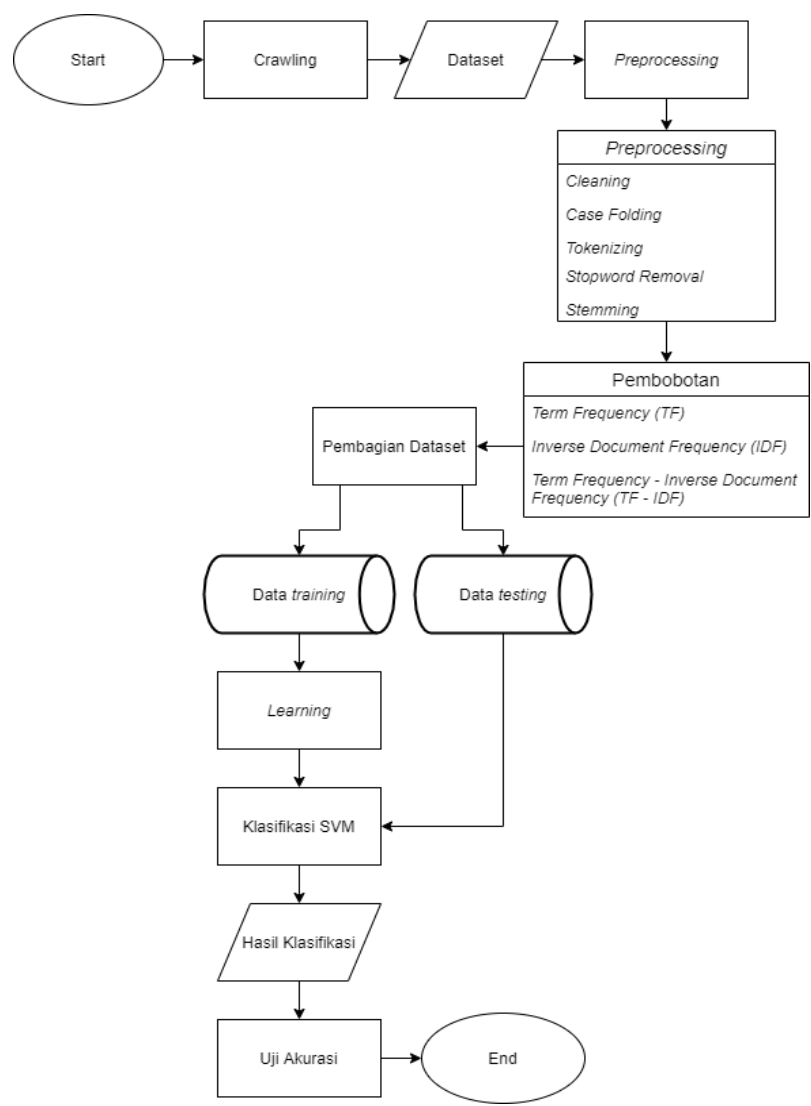

Gambar 2 Sistem secara keseluruhan

Data yang digunakan dalam penelitian ini berupa data berbentuk teks yang didapatkan dari tulisan masyarakat di media sosial Twitter. Data tersebut berupa tweets berisi kata sesuai topik yang sudah ditentukan untuk diteliti yaitu kenaikan tarif BPJS. Tweets data yang diambil dari bulan Januari 2020 sampai Juni 2020. Data tweets yang telah melalui proses preprocessing, sebagian akan digunakan sebagai data training yang merupakan model dalam menentukan hasil sentimen. Jenis data yang digunakan dalam penelitian ini adalah data primer, yaitu data yang diambil langsung oleh penulis dari media sosial twitter. Data tersebut berupa tweets yang mencantumkan kata BPJS dan kenaikan tarif di dalamnya.

Data tweets merupakan dokumen tweets berbahasa Indonesia yang didapat dari hasil crawling.
Crawling merupakan teknik mengumpulkan data pada sebuah website dengan memasukkan Uniform Resource Locator (URL). URL ini menjadi acuan untuk mencari semua hyperlink yang ada pada website, kemudian dilakukan indexing untuk mencari kata dalam dokumen pada setiap link yang ada. Penerapannya crawling menggunakan automation program dan menggunakan Application Programming Interface (API) sebagai jalur komunikasi dalam mendapatkan data, dalampenelitian ini menggunakan Application Programming Interface (API) dari Twitter.

Data hasil crawling kemudian dibagi menjadi dua bagian, yaitu data training dan data testing. Data training merupakan data yang sudah diberi pelabelan sebelumnya, sedangkan data testing merupakan data yang akan diuji menggunakan model yang sudah dibuat. Hasil dari pengujian data testing tersebut merupakan hasil prediksi dari metode yang digunakan.

\subsection{Preprocessing}

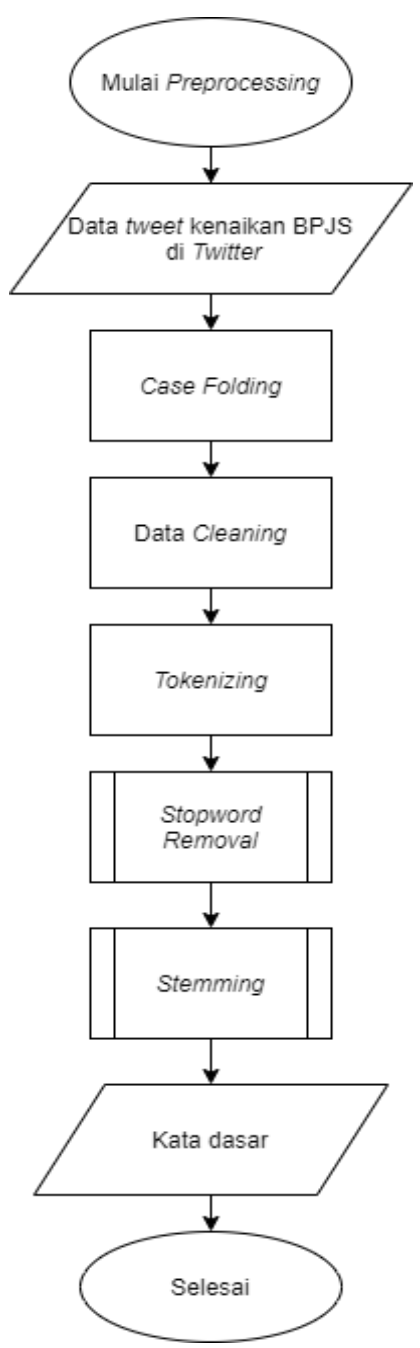

Gambar 3 Preprocessing 
Sentimen analisis merupakan salah satu sub ilmu dari text mining, natural language program, dan artificial intelligence. Proses pada analisis sentiment yaitu untuk memahami, mengekstrak, dan mengolah data teks secara otomatis sehingga menjadi suatu informasi yang bermanfaat[6]. Analisis sentimen merupakan bidang ilmu yang menganalisis pendapat, sikap, evaluasi, dan penilaian terhadap suatu peristiwa, topik, organisasi, maupun perseorangan[7].

Sentimen analisis merupakan salah satu metode untuk menganalisis sebagian data untuk mengetahui emosi manusia. Analisis sentimen dapat dikategorikan kedalam tiga task, yaitu informative text detection, information extraction dan sentiment interestingness classification (polarity identification, emotional). Sentiment classification (positif atau negatif) digunakan untuk memprediksi sentiment polarity berdasarkan data sentimen dari pengguna[8].

Preprocessing sangat menentukan hasil sentimen dengan metode SVM. Preprocessing merupakan tahap awal dari text mining untuk mengubah data sesuai dengan format yang dibutuhkan. Proses ini dilakukan untuk menggali, mengolah dan mengatur infomasi dan untuk menganalisis hubungan tekstual dari data terstruktur dan data tidak testruktur[7].

Tahap preprocessing terdiri atas beberapa proses antara lain adalah case folding, data cleaning, tokenizing, stopword removal, dan stemming. Data komentar Twitter mengenai kenaikan BPJS yang telah dicrawling serta disimpan dalam bentuk .csv selanjutnya akan dibersihkan agar data dapat diklasifikasi lebih lanjut menggunakan metode Support Vector Machine. Tahap awal dalam preprocessing data setelah dilakukan crawling adalah cleansing. Cleansing merupakan proses pembersihan data yang terbagi menjadi dua tahap yaitu case folding dan data cleaning atau symbol removal. Cleansing bertujuan agar data yang akan diolah menjadi lebih bersih dan tidak banyak mengandung noise yang dapat mempengaruhi hasil klasifikasi. Tahapan selanjutnya setelah proses cleaning adalah melakukan tokenizing.

Tokenizing bertujuan untuk mengumpulkan jumlah kata yang menjadi penyusun kalimat di dalam dataset. Data yang dimaksud merupakan kata tunggal, artinya jika ada 2 kata atau lebih di dalam dataset, maka hanya satu yang akan digunakan. Tahapan selanjutnya adalah melakukan stopword removal. Stopword removal adalah proses penyaringan untuk menghilangkan kata yang tidak relevan pada hasil tokenizing dengan cara membandingkannya dengan (stopword list) yang ada. Contoh dari stopword misalnya, kata sambung, artikel, dan preposisi.

Stemming merupakan proses untuk mencari stem (kata dasar) dari kata hasil stopword removal (filtering). Terdapat dua aturan dalam melakukan stemming yaitu dengan pendekatan kamus dan pendekatan aturan[9]. Stemming yang digunakan pada skripsi ini adalah pendekatan kamus, dimana menggunakan library sastrawi. Data yang telah melalui tahapan preprocessing selanjutnya dapat diolah lebih lanjut yakni pemberian bobot pada setiap data tweet yang telah dibersihkan.

\subsection{Klasifikasi}

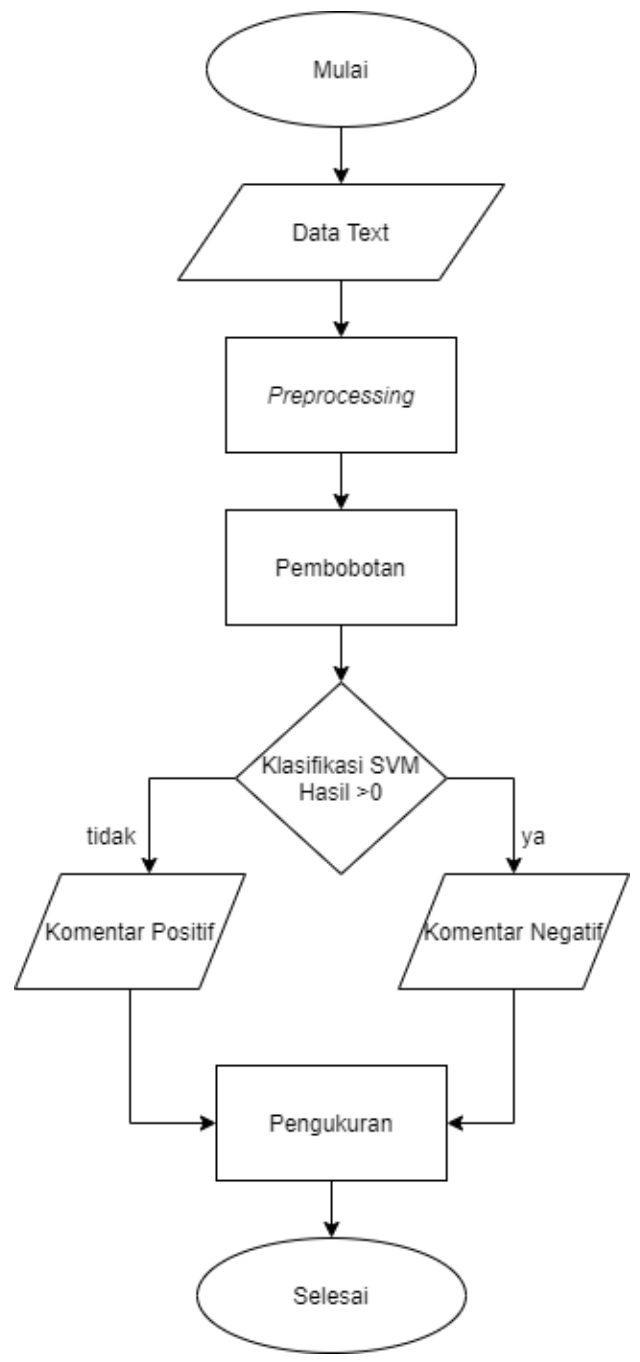

Gambar 4 Klasifikasi SVM

Pada Gambar 4 dijelaskan data berupa kata-kata tweets yang sudah melalui proses preprocessing kemudian dihitung pembobotannya, setelah pembobotan diklasifikasi, apabila kata atau term tersebut bernilai lebih besar sama dengan 0 maka kata tersebut akan dikategorikan sebagai komentar positif, apabila kata atau term bernilai lebih kecil dari 0 maka kata tersebut akan dikategorikan sebagai komentar negatif.

SVM dalam proses klasifikasi bertujuan untuk menemukan garis yang terbaik (hyperplane) untuk membagi dua kelas, kemudian data diklasifikasi 
berdasarkan pada sisi mana garis tersebut muncul. SVM merupakan metode klasifikasi pada metode machine learning (supervised learning) yang memprediksi kelas berdasarkan pola dari hasil proses training yang diciptakan oleh Vladimir Vapnik.

Klasifikasi dilakukan dengan garis pembatas (hyperplane) yang memisahkan antara kelas opini positif dan opini negatif. Secara intuitif, suatu garis pembatas yang baik adalah yang memiliki jarak terbesar ke titik data pelatihan terdekat dari setiap kelas, karena pada umumnya semakin besar margin, semakin rendah error generalisasi dari pemilah. Margin adalah jarak dari suatu titik vektor di suatu kelas terhadap hyperplane[8].

Klasifikasi menggunakan Support Vector Machine akan dimulai dengan mengubah teks menjadi data vektor. Data vektor tersebut mempunyai dua dimensi yaitu (word id) dan bobot. SVM dalam klasifikasi memberikan setiap kata di dalam dokumen data tweets dimensi dan sebuah bobot berdasarkan seberapa penting kata tersebut di dalam dokumen. SVM mementukan garis terbaik yang memisahkan dua kelas di dalam sebuah proses kalsifikasi[10].

Secara sederhana pada konsepnya cara kerja SVM (Support Vector Machine) adalaha mencari Hyperplane terbaik, yang berfumgsi sebagai pemisah dua buah kelas pada input space. Dua kelas, +1 dan 1 , beserta masing-masing pattern terlihat pada gambar dibawah:

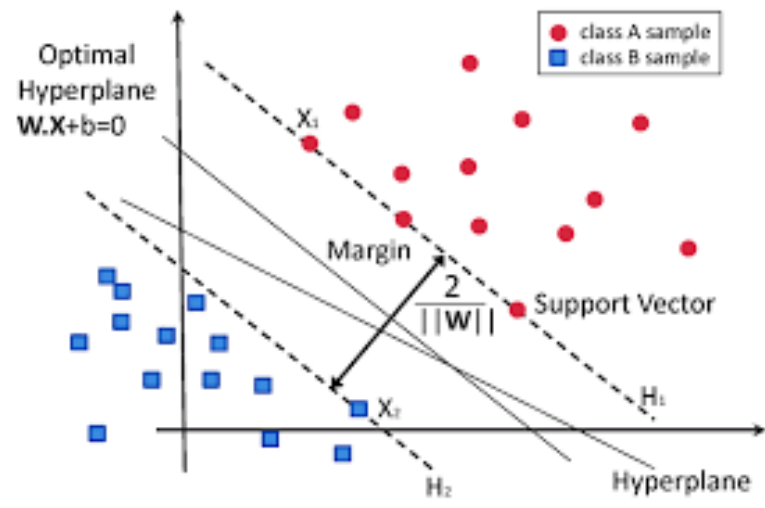

Gambar 5 Grafik Support Vector Machine

Pada Gambar 5 dijelaskan dalam proses mengkalsifikasi untuk mendapat hasil yang baik, hyperplane digunakan sebagai pemisah dua kelas yang berbeda, dengan mengukur margin hyperplane tersebut dan mencari titik maksimalnya[9]. Margin adalah jarak antara hyperplane dengan pattern terdekat dari masing-masing kelas. Pattern terdekat dengan hyperplane disebut dengan support vector pada gambar diatas ditunjukan dengan X1 dan X2 atau point yang berada pada garis putus-putus.
Berdasarkan Gambar 5, bidang pemisah dapat dirumuskan dengan:

$$
\begin{array}{ll}
\boldsymbol{m}=\frac{\mathbf{1 - b}-(-\mathbf{1}-\boldsymbol{b})}{|\boldsymbol{w}|}=\frac{2}{|\boldsymbol{w}|} \\
\mathrm{m} \quad=\text { jarang antara dua bidang } \\
\mathrm{w} \quad=\text { bidang normal } \\
\mathrm{b} \quad=\text { posisi relative terhadap origin }
\end{array}
$$

jarak garis dirumuskan $\mathrm{wx}+\mathrm{b}=\mathrm{c}$ dan ke origin adalah $\frac{(\boldsymbol{c}-\boldsymbol{b})}{|\boldsymbol{w}|}$

Margin $\mathrm{m}$ dimaksimalkan dengan memenuhi konstrain 2 bidang pembatas pada support vector. Bidang pembatas kelas pertama membatasi kelas pertama yang bernilai + sedangkan bidang pembatas kelas kedua membatasi kelas kedua yang bernilai sehingga diperoleh persamaan:

$$
\begin{aligned}
& x_{i} \cdot w+b \geq+1 \text { for } y_{i}=+1 \\
& x_{i} \cdot w+b \leq-1 \text { for } y_{i}=-1
\end{aligned}
$$

Untuk mencari nilai margin terbesar pada hyperplane atau garis pemisah antar dua buah kelas, dapat dirumuskan kedalam optimasi konstrain sebagai berikut:

$$
\begin{aligned}
& \min =\frac{1}{2}|w|^{2} \\
& \text { s.t } y_{i}\left(x_{i} w+b\right)-1 \geq 0
\end{aligned}
$$

Dengan lebih mudah untuk menyelesaikan permassalahan optimasi konstrain daam mulasinya dirubah kedalam formula lagrangian yang menggunakan lagrange multiplier yang diubah menjadi:

$$
\begin{aligned}
\min _{w, b}^{L p}(w, b, a)= & (w, b, a) \\
& =\frac{1}{2}|w|^{2}-\sum_{i=1}^{n} \alpha_{i} y_{i}\left(x_{i} \cdot w+b\right) \\
& +\sum_{i=1}^{n} \alpha_{i}
\end{aligned}
$$

Permasalah pencarian bidang pemisah terbaik dapat dirumuskan sebagai berikut:

$$
\begin{aligned}
& \max _{\alpha} L_{D}=\sum_{i=1}^{n} \alpha_{i}-\frac{1}{2} \sum_{i=1, j=1}^{n} \alpha_{i} \alpha_{j} y_{i} y_{j} x_{i} x_{j} \\
& \text { s.t } \sum_{i=1}^{n} \boldsymbol{\alpha}_{\boldsymbol{i}} \boldsymbol{y}_{\boldsymbol{i}}=\mathbf{0} \boldsymbol{\alpha}_{\boldsymbol{i}} \geq \mathbf{0}
\end{aligned}
$$

Untuk mendapatkan nilai $\boldsymbol{\alpha}_{\boldsymbol{i}}$ yang digunakan untuk menemukan w, maka terdapat $\boldsymbol{\alpha}_{\boldsymbol{i}}$ untuk setiap data yangdigunakan untuk pelatihan. Data untuk 
pelatihan yang mempunyai nilai $\boldsymbol{\alpha}_{\boldsymbol{i}}>\mathbf{0}$ disebut support vector, sedangkan yang memiliki nilai $\boldsymbol{\alpha}_{i}=$ $\mathbf{0}$ adalah sisanya.

Formula pencarian bidang pemisah terbaik atau hyperplane terbaik adalah permasalahan quadratic programming, sehingga nilai maksimum global dari $\boldsymbol{\alpha}_{\boldsymbol{i}}$ akan selalu dapat ditemukan setelah solusi permasalahan quadratic programming ditemukan (nilai $\boldsymbol{\alpha}_{\boldsymbol{i}}$ ), maka kelas dari data pengujian x dapat ditemtukan berdasarkan nilai dari fungsi keputusan:

$$
\begin{aligned}
\boldsymbol{f}\left(\boldsymbol{X}_{\boldsymbol{d}}\right) & =\sum_{i=1}^{n s} \alpha_{i} y_{i} x_{i} x_{d}+\boldsymbol{b} \\
\boldsymbol{x}_{\boldsymbol{i}} & =\text { support vector } \\
\mathrm{ns} & =\text { jumlah support vector } \\
\boldsymbol{x}_{\boldsymbol{d}} & =\text { data yang akan dikalsifikasikan }
\end{aligned}
$$

\subsection{Analisis dan Pengujian Hasil Klasifikasi}

Akurasi klasifikasi merupakan ukuran ketepatan klasifikasi yang menunjukkan performansi teknik klasifikasi secara keseluruhan[6]. Semakin tinggi akurasi klasifikasi berarti performansi teknik klasifikasi juga semakin baik. Kinerja metode klasifikasi dalam melakukan pengkasifikasian menggambarkan seberapa baik metode tersebut dalam mengkasifikasikan data.

Confusion matrix merupakan salah satu metode yang dapat digunakan untuk mengukur kinerja suatu metode kalsifikasi. Pada dasarnya confusion matrix mengandung informasi yang membandingkan hasil kalsifikasi yang dilakukan oleh sistem dengan hasil klasifikasi yang seharusnya[6]. Pada pengukuran kinerja menggunakan confusion matrix terdapat 4 istilah yang merepresentasikan hasil proses klasifikasi, seperti yang terlihat pada Tabel 1:

Tabel 1 Confussion Matrix

\begin{tabular}{|c|c|c|}
\hline \multirow{2}{*}{ Aktual } & \multicolumn{2}{|c|}{ Prediksi } \\
\cline { 2 - 3 } & Positif & Negatif \\
\hline Positif & TP & FN \\
\hline Negatif & FP & TN \\
\hline
\end{tabular}

Keterangan :

TP : True Positive (Jumlah prediksi benar pada kelas positif)

FP : False Positive (Jumlah prediksi salah pada kelas positif)

FN : False Negative (Jumlah prediksi salah pada kelas negatif)
TN : True Negative (Jumlah prediksi benar pada kelas negatif).

Berdasarkan nilai dari keempat klasifikasi tersebut, maka akan diperoleh nilai akurasi, presisi, dan recall. Nilai akurasi adalah nilai yang mengambarkan seberapa akurat metode yang digunakan dalam melakukan klasifikasi dengan benar dari keseluruhan data yang ada. Nilai presisi menggambarkan jumlah data kategori positif yang diklasifikasikan secara benar dibagi dengan total data yang dikalsifikasi positif. Nilai recall menunjukan berapa persen data kategori positif yang terklasifikasikan dengan benar.

$$
\begin{aligned}
& \text { Akurasi }=\frac{T N+T P}{T N+T P+F N+F P} \times 100 \% \\
& \text { Presisi }=\frac{T P}{T P+F P} \times 100 \% \\
& \text { Recall }=\frac{T P}{T P+F N} \times 100 \%
\end{aligned}
$$

\subsection{Pembuatan Visualisasi Hasil Sentimen Analisis}

Visualisasi hasil klasifikasi sentimen pada penelitian ini menggunakan pie diagram. Pie diagram adalah gaya grafik sederhana yang berguna untuk menggambarkan bagian-bagian dari keseluruhan data. Pie diagram adalah bagan berdasarkan data numerik untuk menunjukkan proporsi dalam persentase. Pie diagram pada penelitian ini digunakan untuk mempermudah melihat proporsi pensentase jumlah dataset yang terklasifikasi kedalam komentar positif dan komentar negatif.

\section{HASIL DAN PEMBAHASAN}

\subsection{Hasil Crawling Data}

Pada proses crawling data twitter pada penelitian ini menggunakan bantuan aplikasi google spreadsheet dan serta tools add-ons yaitu twitter achiver. Add-Ons adalah salah satu komponen opsional yang terdapat didalam menu google spreadsheet, add-ons biasanya digunakan untuk menambah program atau fungsi-fungsi tambahan laiinya pada file Excel, Word, ataupun file lainnya yang dibuat menggunakan google spreadsheet. AddOns yang digunakan untuk crawling data twitter adalah Tweet Archiver.

Twitter archiver merupakan salah satu add-on dari Google Chrome yang bisa digunakan untuk mengumpulkan data tweet dengan keyword, hashtag, atau mention tertentu yang kemudian akan disimpan kedalam Google Spreadsheet. Secara berkala twitter archiver akan mengumpulkan tweet baru sesuai kriteria pencarian yang sudah disetting dan google 
spreadsheet akan otomatis mengupdate tweet-tweet baru yang ada jika tweet tersebut sesuai dengan rule yang telah dibuat sebelumnya.

Rule adalah kriteria yang akan digunakan pada proses crawling data. Data yang dicrawling akan sesuai dengan rule yang telah di tentukan kriteria pencarian (search rule) dapat dilakukan dari yang sangat sederhana sampai yang kompleks. Untuk mendapatkan data mengenai kenaikan tarif BPJS Kesehatan dapat menginputkan filter terkait keyword kenaikan BPJS.

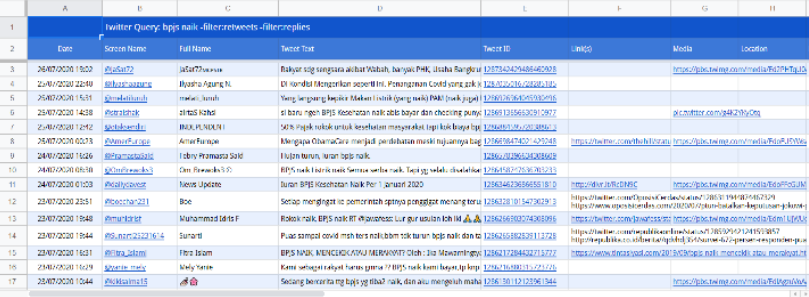

Gambar 6 Hasil Dashboard Pada Indeks KAMI

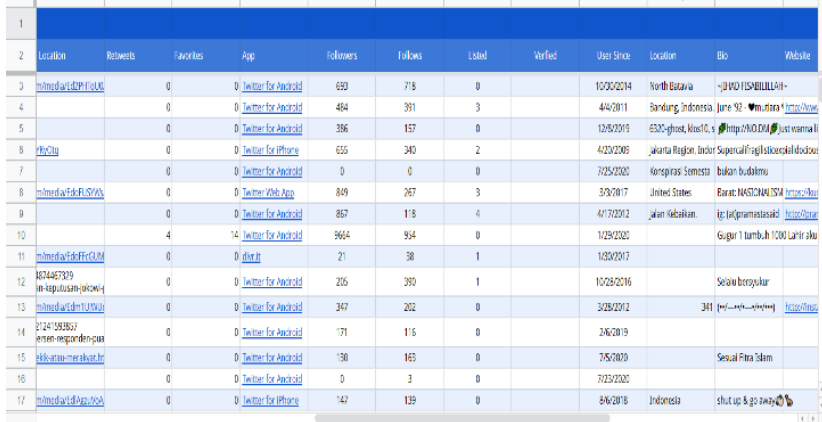

Gambar 7 Hasil Dashboard Pada Indeks KAMI

Gambar 6 dan Gambar 7 merupakan hasil dari proses crawling data menggunakan twitter archiver. Data hasil crawling akan sesuai dengan rule yang telah ditentukan sebelumnya. Twitter achiver dapat memperoleh data tweet dengan informasi yang sangat lengkap. Data hasil crawling dapat disimpan dalam berbagai jenis format salah satunya adalah CSV (Comma Separated Values).

\subsection{Hasil Klasifikasi}

Proses pembentukan data training pada penelitian ini menggunakan metode cross-validation, dengan jumlah validasi dari nilai $x$ yang di uji cobakan sebanyak 1-10 kali. Data testing pada penelitian ini digunakan sebanyak $20 \%$ dan data training sebanyak $80 \%$ dari total keseluruhan sample data yang ada. Gambar 8 dan Gambar 9 menunjukan hasil klasifikasi yang dilakukan oleh SVM. Berdasarkan diagram pada Gambar 9 terlihat bahwa dari total 671 data tedapat 271 data yang termasuk kategori positif serta 400 data termasuk kedalam kategori sentimen negatif.

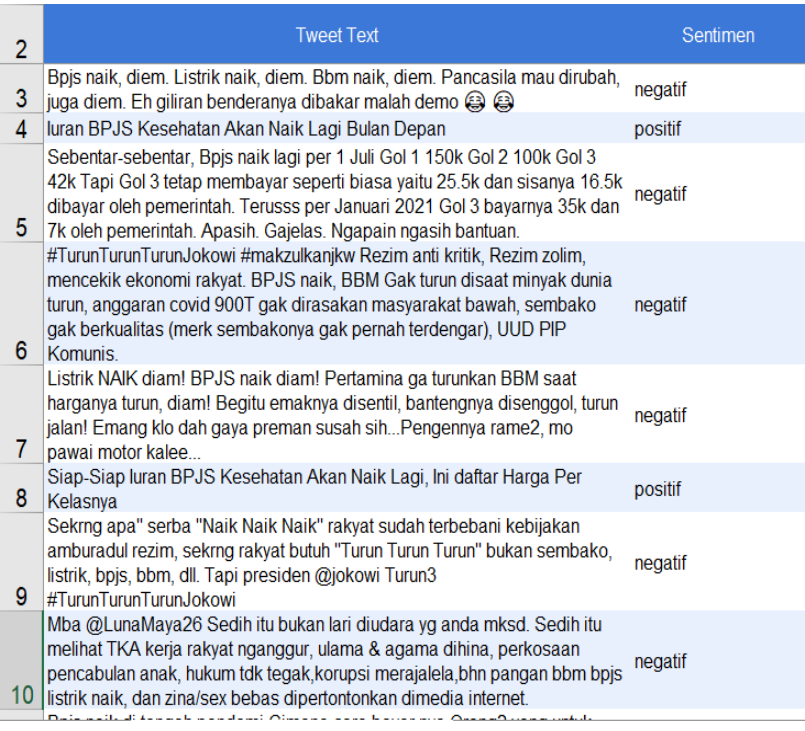

Gambar 8 Hasil Klasifikasi Sentimen

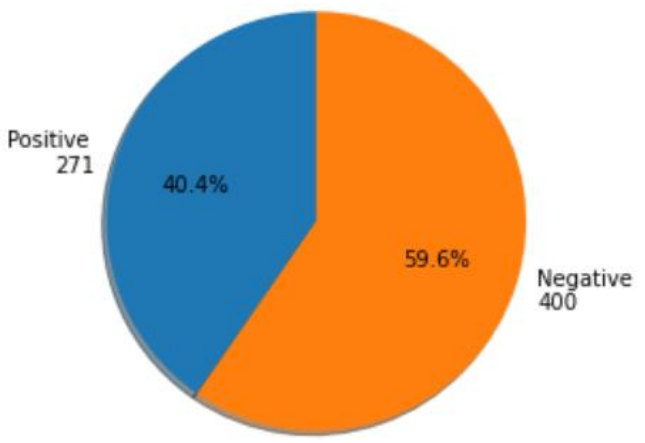

Gambar 9 Diagram Hasil Klasifikasi

\subsection{Hasil Pengujian}

Pada Gambar 10 menunjukan hasil perhitungan dari confusion matrix. Pengujian dilakukan untuk mengetahui tingkat akurasi klasifikasi hasil sentimen analisis menggunakan metode SVM pada kasus kenaikan tarif BPJS Kesehatan.

$\begin{array}{rrrrr} & \text { precision } & \text { recall } & \text { f1-score } & \text { support } \\ 0 & 0.90 & 0.96 & 0.93 & 376 \\ 1 & 0.94 & 0.87 & 0.90 & 295 \\ \text { accuracy } & & & 0.92 & 671\end{array}$

accuracy_score $=0.9195230998509687$

Number of Data Frame Test : 671

Gambar 10 Hasil Tingkat Akurasi SVM 
Berdasarkan nilai dari keempat klasifikasi tersebut, maka akan diperoleh nilai akurasi, presisi, dan recall. Nilai akurasi adalah nilai yang mengambarkan seberapa akurat metode yang digunakan dalam melakukan klasifikasi dengan benar dari keseluruhan data yang ada. Nilai presisi menggambarkan jumlah data kategori positif yang diklasifikasikan secara benar dibagi dengan total data yang dikalsifikasi positif. Nilai recall menunjukan berapa persen data kategori positif yang terklasifikasikan dengan benar.

\section{Tabel 2 Confusion Matrix}

\begin{tabular}{|c|c|c|}
\hline Kelas & $\begin{array}{c}\text { Terklasifikasi } \\
\text { Positif }\end{array}$ & $\begin{array}{c}\text { Terklasifikasi } \\
\text { Negatif }\end{array}$ \\
\hline Positif & 256 & 361 \\
\hline Negatif & 15 & 39 \\
\hline
\end{tabular}

Tabel 2 menunjukan hasil klasifikasi sentimen menggunakan metode SVM yang telah dikelompokan menggunakan tabel confusion matrix.

\section{KESIMPULAN}

Hasil penelitian yang dilakukan menunjukan metode SVM memiliki tingkat akurasi atau tingkat kedekatan antara nilai prediksi dari sistem dengan nilai aktual yang mencapai $92 \%$ pada proses pengujian meggunakan confussion matrix. Hasil precision atau tingkat ketepatan antara informasi yang diminta oleh pengguna dengan jawaban yang diberikan oleh sistem pada sentimen positif sebesar $94 \%$, recall yang merupakan nilai rasio prediksi benar positif dibandingkan dengan keseluruhan data yang benar positif sebesar $87 \%$ dan hasil precision pada sentimen negatif sebesar $90 \%$, serta recall pada sentimen negatif sebesar $96 \%$.

Berdasarkan hasil klasifikasi menggunakan algoritma SVM pada 671 sample data tedapat 271 data yang setuju dengan kebijakan yang dibuat serta 400 data yang tidak setuju terhadap kebijakan. Hal tersebut menunjukan bahwa sentimen masyarakat terkait dengan kebijkan BPJS Kesehatan yang menaikan tarif pembayaran cenderung bernilai negatif atau tidak setuju.

\section{REFERENSI}

[1] K. M. Carley, M. Malik, M. Kowalchuck, J. Pfeffer, and P. Landwehr, "Twitter Usage in Indonesia," SSRN Electron. J., no. August 2016, 2018,

[2] K. M. Carley, M. Malik, P. M. Landwehr, J. Pfeffer, and M. Kowalchuck, "Crowd sourcing disaster management: The complex nature of Twitter usage in Padang Indonesia," Saf. Sci., vol. 90, pp. 48-61, 2016

[3] A. Pak and P. Paroubek, "Twitter as a corpus for sentiment analysis and opinion mining," Proc. 7th Int. Conf. Lang. Resour. Eval. Lr. 2010, pp. 1320-1326, 2010

[4] A. Z. Amrullah, A. S. Anas, M. Adrian, J. Hidayat, F. Teknik, and U. Bumigora, "Analisis Sentimen Movie Review Menggunakan Naive Bayes Classifier Dengan Seleksi Fitur Chi Square," J. BITe J. Bumigora Inf. Technol., vol. 2, no. 1, pp. 4044, 2020

[5] U. Rofiqoh, R. S. Perdana, and M. A. Fauzi, "Analisis Sentimen Tingkat Kepuasan Pengguna Penyedia Layanan Telekomunikasi Seluler Indonesia Pada Twitter Dengan Metode Support Vector Machine dan Lexion Based Feature," J. Pengemb. Teknol. Inf. dan Ilmu Komput. Univ. Brawijaya, vol. 1, no. 12, pp. 1725-1732, 2017, [Online]. Available: http://j-ptiik.ub.ac.id/index.php/jptiik/article/view/628.

[6] A. D. Hartanto and N. K. Fitriyani, "Analisis Sentimen Terhadap Tokoh Publik Menggunakan Support Vector Machine," MEANS (Media Inf. Anal. dan Sist., vol. 5, no. 1, pp. 8-12, 2020, [Online]. Available: http://ejournal.ust.ac.id/index.php/Jurnal_Me ans/.

[7] Y. X. Chu, X. G. Liu, and C. H. Gao, "Application of Support Vector Machine in Bioinformatics," Proc. 2011 Chinese Control Decis. Conf. CCDC 2011, pp. 842-847, 2011

[8] R. Valentini, P. Siwabessy, A. Herdiani, and A. Romadhony, "Analisis Sentimen Masyarakat Terhadap Hasil Kerja Petahana Dalam Kaitan Dengan Pemilihan Presiden tahun 2019 Pada Sosial Media Twitter Menggunakan Support Vector Machine ( SVM )," vol. 6, no. 2, pp. 8625-8636, 2019.

[9] M. S. Utomo, "Implementasi Stemmer Tala pada Aplikasi Berbasis Web," J. Teknol. Inf. Din., vol. 18, no. 1, pp. 41-45, 2013.

[10] Q. Han, J. Guo, and H. Schütze, "CodeX: Combining an SVM classifier and character $\mathrm{N}$-gram language models for sentiment analysis on twitter text," *SEM 2013 - 2nd Jt. Conf. Lex. Comput. Semant., vol. 2, no. SemEval, pp. 520-524, 2013. 